\title{
Not getting a word in edgeways?: Language, gender, and identity in a British comedy panel show
}

\begin{abstract}
Despite the great strides made over the past thirty years by female comedy performers, their status in a male-dominated industry has typically been marginal. This is coupled with the widespread view that even women who do appear on mainstream comedy face the challenge of getting their voices heard in an arena where it is often the loudest voice that wins. In order to investigate claims that female comedians contribute less than male comedians on comedy panel shows, this article presents the findings of a sociolinguistic analysis of the British show Mock the Week, drawing on an XML-annotated corpus of the transcripts of series five. Rather than viewing features such as talkativeness and interruption solely as a substantiation of conversational dominance (cf. Brand 2009), we suggest that these could also be understood as strategies in the production of humour in the context of comedy panel shows. In addition to genre-specific considerations, our results show that the use of these features on Mock the Week is influenced by an interplay of social factors, rather than gender alone. Overall, this study could act as a catalyst for writers and production companies to use more linguisticallyinformed approaches to comedy show scripting, particularly in relation to issues of linguistic and representational inequality.
\end{abstract}

\section{Keywords:}

sociolinguistics, conversational dominance, talkativeness, interruption, gender, situational role, comedy panel show, corpus linguistics

\section{Introduction}

Over the past thirty years, female comedy performers have typically held an unstable and precarious position in a male-dominated industry, despite making considerable advances in strengthening their status in the comedy circuit (Greengross and Miller, 2009: 83). Not only 
have women traditionally been the target of sexist jokes (Bemiller and Schneider, 2010), sexual innuendo (Simpson, 2000), and stereotypically viewed to be 'less funny' than men (Bird, 2010; Kalviknes, 2010), they also remain under-represented in mainstream television comedy, comedy panel shows, and live stand-up performances (Benedictus, 2012; Rainey, 2012; Feeney, 2013). This marginality is combined with a widespread social discourse that women who do appear on mainstream comedy face the challenge of getting their voices heard in an arena where it is often the loudest voice that wins.

The lack of female representation in mainstream comedy and the difficulties women face within the industry is an ongoing debate. For example, a number of well-known British comedians, such as Jo Brand, Victoria Wood, Sandi Toksvig, Miranda Hart, and Kate Smurthwaite, have recently commented on the difficulties of being a woman on the comedy circuit, including the problems with breaking into the industry, the prevalence of sexist jokes by male comedians, and being the 'token female' on primarily male-dominated shows. They have also criticised the aggressive interactional norms that govern television comedy shows, including interruptions, failure to respond to jokes, and talking too much. In particular, Victoria Wood commented that comedy panel shows "rely on men topping each other, or sparring with each other, which is not generally a very female thing” (Khan, 2009), while Sandi Toksvig suggested that “women's jokes aren't about trying to top the last person or 'win' the game" (Martin, 2008). Taken together, these comments call to mind the picture of the “"all-purpose male oppressor' who talks too much, interrupts and generally dominates conversations with women" (Johnson, 1997: 11), a picture which generally aligns with the broader cultural stereotype that men compete and women co-operate (cf. Cameron, 2007: 8).

Despite the degree of public attention and social commentary about panel shows, however, very little research has focused on this particular sphere of the entertainment industry. To address this gap, we draw on data collected from series five of the British television panel show Mock the Week to critically examine the linguistic practices of male and female comedians and to evaluate how features such as talkativeness and interruption are deployed in interaction. In the first part, we discuss Mock the Week in more detail and outline some of the criticisms directed toward the show. We also discuss the marginality of women in comedy and some of the explanations that have been given to legitimate it. In the second part, we present our discussion of the primary variables we examine, followed by the results of our 
linguistic analysis (both quantitative and qualitative). Lastly, we discuss some of the implications this work might have beyond academia and its potential contribution to industry practices.

\section{Mock the Week}

Mock the Week is a popular thirty-minute British comedy panel show which has been running since 2005 and is currently in its fourteenth series. It involves two teams of three panellists, with each team comprising one permanent panellists (i.e. panellists who appear in every episode in a series) and two guest panellists (i.e. panellists who have only occasional appearances in a series). ${ }^{1}$ These two teams compete against one another in answering a series of questions about current affairs in the UK and further afield. Points are awarded to the team who not only answers the questions correctly but is also the funniest in doing so (as decided by the show's host, Dara O'Briain). There is, however, no specific scoring system and the 'winner' is typically decided at random. The structure of the show varies from episode to episode, but generally includes quick answer rounds, stand-up routines, and improvisation.

Although the jokes exchanged appear to be fast-paced and the show is recorded in front of a studio audience, there are a number of issues worthwhile raising. The first issue is that the final broadcast version is in fact heavily edited. Estimates have suggested approximately three hours of footage are trimmed down to thirty minutes of screen-time (Nissim, 2011), with many of the jokes pre-scripted (Logan, 2013). That the show is edited is important to consider, since the final broadcast version may not be wholly representative of what actually happens during recording. For example, although a panellist may contribute multiple jokes during the full recording period, these contributions may be edited out for the purposes of flow, length and so on. While it could be argued that any analysis based on edited data can only be partial, we would suggest that since editorial decisions guide the construction of the version broadcast in the public domain, there is a need to critically examine the final product.

The second issue is that although the talk produced on the show appears to be

\footnotetext{
${ }^{1}$ In later series, one team comprises two permanent panellists and one guest panellist while the other team comprises only one permanent panellist and two guest panellists.
} 
spontaneous, much of it is scripted rather than 'off-the-cuff' (Crawley 2013). Of course, such constructed (or 'performed') data is becoming more of a focus for sociolinguistic analyses (cf. Queen 2013, 2015), but it would be reasonable to suggest that the talk in Mock the Week (and comedy panel shows more generally) is not characteristic of the 'casual conversations' (or even 'institutional conversations') usually considered by linguists (cf. Heritage 2005: 104). For example, the show often has multiple panellists vying for control of the conversational floor for the purposes of delivering a humorous contribution. But contrary to 'ordinary' or 'casual' conversation, it is difficult to argue that panellists deploy humour for the purposes of rapport-management, group solidarity, or social bonding (cf. Knight 2013; Attardo 2015: 176). Instead, the panellists are effectively 'at work,' with the primary aim of their contributions being to elicit laughter, both from other panellists and from the audience. Ultimately, their relative standing within and outwith the show (and their potential earning power and future employability) hinges on how funny their contributions are deemed to be.

\section{Mock the Week and women in comedy}

In recent years, Mock the Week has come in for particular criticism regarding institutional sexism, with questions being raised about whether female panellists are afforded the same opportunities to contribute as male panellists. Comedian Jo Brand famously quit the show in June 2009, arguing that women do not go on panel shows because "they won't get a word in edgeways ... they don't like competing for air time ... and they may be patronised, marginalised or dismissed," and that both male and female comedians had stopped appearing on the show because "we just didn't like the prospect of having to bite someone's foot off before they let us say something" (Brand, 2009)2.

Brand's comments here raise an interesting claim concerning the difficulty female comedians have in contributing to ongoing talk amidst competition from male comedians, part of the broader discourse of the visibility of women's voices in the public sphere (see

\footnotetext{
${ }^{2}$ Interestingly, Brand (2009) also makes the point that regular panellists on shows like Mock the Week "can be terrifying. They own that space and many guest comedians suspect they are favoured in the edit, while their own hilarious jokes end up being ejected into the ether." We return to this later in our discussion.
} 
Cameron, 2006 for a more detailed discussion of this issue). On the one hand, this failure to participate has been linked to the supposed deficit of women's comedic ability, rather than any structural inequalities in the comedy industry (see Burnett, 2014 and Lang, 2015 for an overview of this discussion). This type of discourse emerges in various guises, from Robin Lakoff's (in)famous claim that "women have no sense of humor" (Lakoff, 1975: 56) to Christopher Hitchen's treatise on "why women aren't funny” (Hitchens 2007). Occasionally, such views are 'supported' by reference to social biology and evolutionary psychology (e.g. Bressler et al., 2006; Gambacorta and Ketelaar, 2013; Wilbur and Campbell, 2013; Greengross, 2014), where men's 'skill in humour' is typically seen as a positive sexual selection trait. As Cameron (2007: 111) argues, however, evolutionary biological explanations are not explanations at all, since they "presuppose what [they are] meant to be explaining."

On the other hand, Brand's comments draw on the ideology of the supposed conversational dominance of male speakers, where opportunities for female speakers to contribute are closed down. This view of men's language as a substantiation of their more dominant position in contemporary society was for several decades a major focus within language and gender research (cf. Spender, 1980; Henley and Kramarae, 1991). Such claims have been made in reference to a range of linguistic phenomena, including control of the conversational floor (Edelsky, 1981; Woods, 1989), silence (Coates, 2004: 122-123), topic management (Fishman, 1978; Leet-Pellegrini, 1980), questions (Harris, 1995), and interruptions (Zimmerman and West, 1975; Brooks, 1982; Bohn and Stutman, 1983; West, 1984; Smith-Lovin and Brody, 1989). As a number of scholars have pointed out, however, the dominance approach can be criticised on the grounds that it posits a relatively onedimensional relationship between linguistic form and interactional meaning (cf. Tannen, 1983; Goldberg, 1990; Anderson and Leaper, 1998; McElhinny, 2003; see Cameron, 2006: 77-78 for a fuller discussion of conversational relativity).

In contrast to the two positions outlined above, we adopt a social constructionist perspective in this paper. As such, we view the differential use and evaluation of humour by men and women not as deriving from evolutionary pressures, but rather from a host of social pressures that devalue 'funny women' in contemporary western society. More concretely, men and women face very different social expectations when it comes to comedy and there exist strong cultural scripts of gender-appropriate behaviour related to humour. For example, 
men in contemporary western culture are expected be funny, and a great deal of pressure is typically placed on men to produce humorous stories and anecdotes, particularly in all-male groups (cf. Coates, 2003). Not only is humour explicitly bound up with notions of being a 'real man' (Kehily and Nayak, 1997; Mullany, 2010), men are also more likely to be evaluated negatively by their peer-group if they are not 'funny' (Collinson, 1988). Conversely, there is limited social pressure on women to be funny, they are generally not afforded the same kind of positive social evaluation as men with regards to humour, and they are given limited opportunities to participate in mainstream comedy (cf. Smurthwaite, 2012).

Second, adopting a social constructionist approach means that we can develop a more nuanced picture of the role language plays in the construction of social identity, instead of positing a straightforward male/female dichotomy in the use of specific linguistic features. As Eckert and Podesva (2011: 7) and Bamman et al. (2014: 125) point out, the 'categorisation' approach to language and gender, while analytically tempting, omits the different ways through which identity (of which gender is only a part) can be linguistically and discursively constructed. Before presenting our analysis, we first turn to a more detailed discussion of our data and the variables under consideration.

\section{Data used for this project}

Although Mock the Week is currently in its fourteenth season, we restrict our focus in this article to episodes 1 to 10 of series five, for several reasons. First, it combined the highest number of females in one series with the lowest number of males, making the split between male and female guest panellists reasonably equitable by contrast to later series, which sometimes have only two female panellists across the entire run of episodes. Over the course of series five, there were five female guest panellists and nine male guest panellists (see Figure 1). Second, while earlier series have at least one female panellist in each episode, these series have a smaller number of episodes, considerably limiting the size of the potential dataset. Last, series five provided us with a reasonably sized dataset of 56,353 transcribed words. 


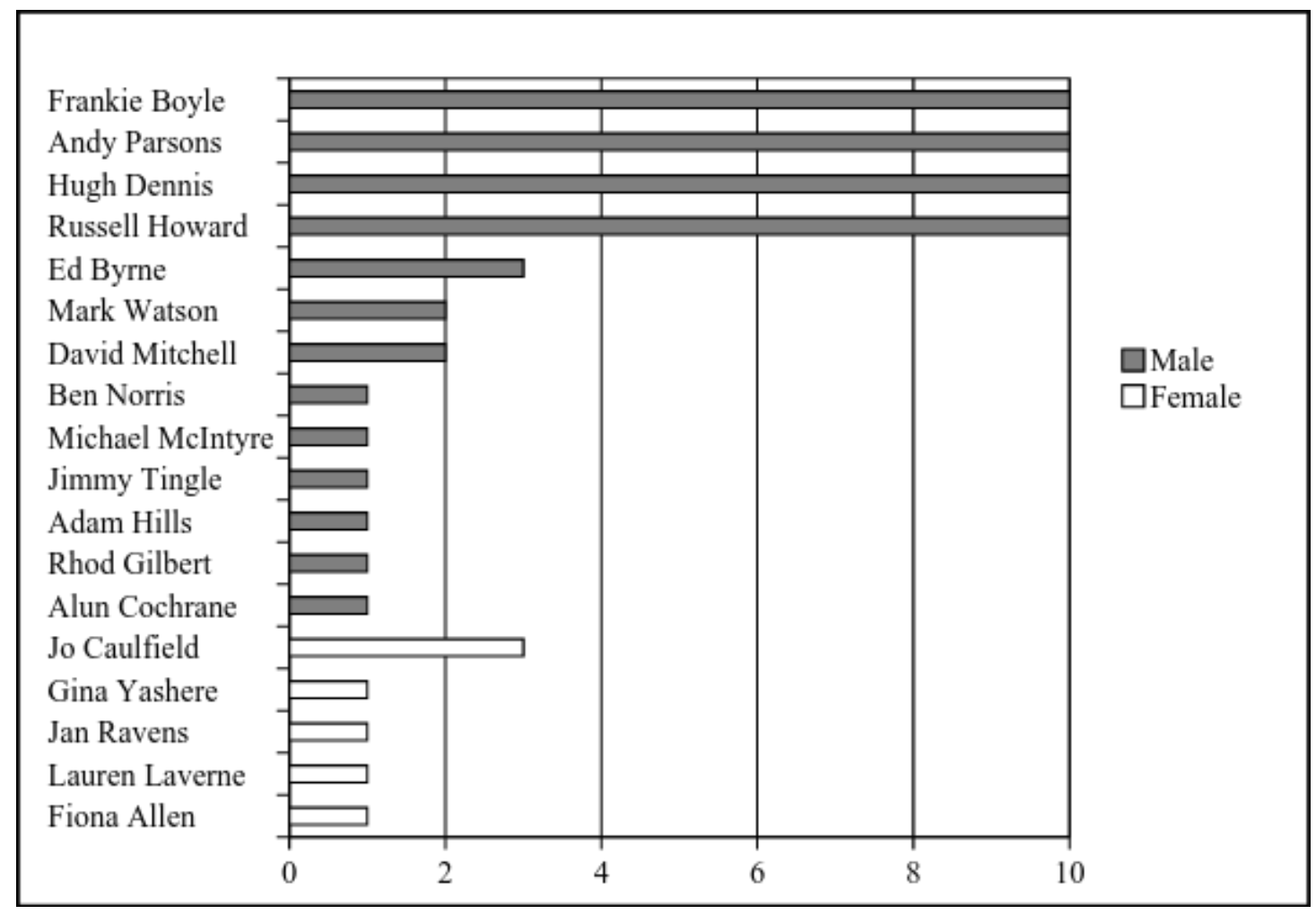

Figure 1. Mock the Week, series five panellists and appearances (episodes 1-10)

In order to analyse the linguistic features outlined below in section 5 , the data were first transcribed by four transcribers (the authors and two student assistants, Eilis Foley and April Tricker). The data were then cross-checked for accuracy by the two lead authors and any discrepancies were corrected after consultation. These final transcripts were further annotated with XML tags, an approach widely used in corpus linguistics but less so in sociolinguistic analyses (cf. Baker 2010).

Our decision to produce an XML annotated corpus was inspired by several considerations: first, we wanted to create a corpus whose tagging allowed us to determine the total number of words (and turns) spoken by each participant in a reliable manner, so that we could normalize our findings accordingly. Additionally, the specific linguistic features that we intended to study, that is the total number of interruptions and their functions, had to be searchable for each participant and speaker sex in an easy and straightforward manner. By marking up the data using XML, it was possible to add tags that signalled interruptions. More specifically, each interruption is introduced by an opening tag, such as <interruption by="speaker" with ="speaker" function="x">, and closed by a closing tag </interruption>. 
The tags indicate who interrupts and who is being interrupted and provide information about the function of the interruption. In the transcripts, these tags are included in the turn of the speaker being interrupted and in the turn of the speaker responsible for the interruption. While this tagging is tailored to the needs of the present study, the tag set is at the same time flexible enough to offer the opportunity of expanding it in the future and for the data to be re-used, opening up the possibility of sharing our corpus with the academic community.

\section{Analysis: Talkativeness and Interruption}

For the purposes of this study, we focus our attention on two main linguistic features: talkativeness and interruption. Both of these features rely on the turn-taking system developed by Sacks et al. (1974) which proposes that, in general, speakers take individual turns contributing to a conversation, with each turn viewed as a holding of the conversational floor. When interlocutors have equal rights to this floor, the talking time, for example, should be roughly equal across all interlocutors.

In their foundational discussion of turn-taking and conversational structure, Sacks et al. (1974) argue that a change in the control of the floor can only happen at a Transition Relevance Place (TRP). TRPs are usually identified by falling intonation or explicit selection of the next speaker through the use of names or titles. An interruption, however, happens when Speaker A begins his or her turn before Speaker B arrives at a TRP, ultimately violating the turn-taking paradigm. As discussed previously, since an interruption by one speaker prevents another speaker from completing his or her turn, early sociolinguistic research viewed interruption as an example of speaker dominance (Octigan and Niederman, 1979; Smith-Lovin and Brody, 1989: 425).

In this study, we take a more nuanced view of the meaning of the panellists' linguistic practice. In terms of talkativeness, we were primarily interested in the volume of talk produced by male and female panellists, adding to our analysis a panellist's number of appearances in the series in order to investigate whether familiarity with the panel format might be a factor in the number of words and turns produced. This allows us to investigate whether being a regular panellist, as opposed to a guest panellist, has an effect on talkativeness. For interruptions, we follow the example set by Smith-Lovin and Brody (1989) 
and Goldberg (1990) where interruptions are categorised by their affective role. In our case, we adopt the categories of 'disruptive,' 'supportive' and 'neutral,' depending on whether an interruption is used to cut another speaker's turn off, support their contribution by adding to it, or do neither of these. In addition to analysing the number of interruptions produced in light of the number of times a panellist appears on the show, adopting these three categories allows us to offer a more nuanced interpretation of the data.

\subsection{Speech volume and conversational contribution}

The current study, as stated above, focuses on the Mock the Week episodes 1-10 of series five. The size of the corpus of XML annotated transcripts amounts to 56,353 words, which equals 2,324 speaker turns. Table 1 gives the distribution of these turns and words according to speaker sex.

Table 1. Turn and word counts by speaker sex

\begin{tabular}{|c|c|c|c|c|}
\hline Speaker sex & Turns & & Word Counts & \\
\hline FEMALE & 125 & $(5 \%)$ & 2,295 & $(4 \%)$ \\
\hline MALE & 2,199 & $(95 \%)$ & 54,058 & $(96 \%)$ \\
\hline TOTAL & 2,324 & & 56,353 & \\
\hline
\end{tabular}

As Table 1 shows, the number of turns by male panellists $(2,199)$ is considerably higher than that by females (125), with female turns amounting to $5 \%$ of the total. Equally, the majority of words are produced by male speakers $(54,058)$, with the female word count $(2,295)$ amounting to only $4 \%$ of the total number of words.

Table 1 thus shows a considerable imbalance with regard to the amount of speech produced by male and female panellists. This distribution is, however, partly predetermined by the set-up of the show, which in series five has four permanent male panellists and one male host. As there is always at least one male guest panellist, each episode has a minimum of six male panellists; in fact, episodes five, six and eight did not have a single female panellists. As a consequence, the imbalance in male and female appearances and word count, which one would normally try to avoid when compiling a corpus, is due to the choice of data.

Table 2 shows the distribution of turns and words per participant on the show. The column giving the participant's name also includes an indication of their total number of 
appearances across the ten episodes of series five in brackets. In the current data, the total number of female words and turns was thus produced by five female panellists, four of whom appeared only once and one of whom (Jo Caulfield) appeared three times in series five. In addition to the host and four regulars appearing in each of the ten episodes, nine further male comedians were involved; one of them three times (Ed Byrne), two of them twice (Mark Watson and David Mitchell), and six only once each. Thus there were seven appearances by female panellists and sixty-three by male panellists, out of a total of seventy appearances in all ten episodes.

Table 2. Turn and word counts per participant

\begin{tabular}{lrr|lrr} 
Male panellists & Turns & Words & Female panellists & Turns & Words \\
\hline Dara O'Briain (10) & 669 & 17,215 & Jo Caulfield (3) & 51 & 1,102 \\
Frankie Boyle (10) & 441 & 10,757 & Lauren Laverne (1) & 23 & 326 \\
Hugh Dennis (10) & 299 & 6,110 & Jan Ravens (1) & 20 & 375 \\
Russell Howard (10) & 292 & 6,581 & Gina Yashere (1) & 20 & 332 \\
Andy Parsons (10) & 191 & 5,557 & Fiona Allen (1) & 11 & 160 \\
Ed Byrne (3) & 71 & 1,919 & Total & 125 & 2,295 \\
Mark Watson (2) & 56 & 1,059 & & & \\
David Mitchell (2) & 51 & 1,175 & & & \\
Michael McIntyre (1) & 30 & 919 & & & \\
Adam Hills (1) & 26 & 896 & & & \\
Ben Norris (1) & 21 & 427 & & & \\
Jimmy Tingle (1) & 18 & 521 & & & \\
Rhod Gilbert (1) & 18 & 473 & & & \\
Alun Cochrane (1) & 16 & 449 & & & \\
Total & 2,199 & 54,058 & & & \\
\end{tabular}

As the host of the show, Dara O'Briain has a considerably higher total number of turns and words spoken than all other panellists, more than twice as high as that of three of the four regular male panellists, i.e. Hugh, Russell and Andy. The only regular panellist close to Dara's speech volume is Frankie Boyle, who speaks 441 turns and almost 11,000 words over ten episodes. While Hugh Dennis and Russell Howard speak with similar frequencies overall, Andy Parsons is an outlier as he only produces 191 turns in total. Given that he is a regular 
and should have more opportunities to contribute to the show than a guest, this is a partly surprising finding.

Scrutinising the seven episodes that feature a female guest panellist, one discovers that they usually place towards the bottom of the list in terms of turn and word count: in episodes one, four and seven women have the lowest turn and word counts overall. In episode two, they appear in second-to-last place, with Andy Parsons speaking least of all panellists. In episodes three, nine, and ten their turn count is higher than Andy's, but their word count is lower. For example, in episode two Jo Caulfield produces around 9\% of the overall word count, which is higher than the contributions by the permanent panellist Andy (5\%). In episode ten, on the other hand, Gina Yashere contributes only $6 \%$ of the total word count, followed by Andy with 8\%. Thus, studying the contributions of individual panellists per episode shows that women tend to get less floor time than men and rank mainly at the bottom with regard to word count; that is to say that they are granted or make use of the least speaking time.

In addition to speaker sex differences, the above discussion points to the role of a participant on the panel as a further variable influencing the number of contributions made. In terms of role, one can distinguish between permanent and guest panellists. Figure 2 shows the turn count per panellist over the ten episodes. Guest panellists were combined into two groups; Guest 1 is a combination of the different guest panellists contributing the least to an episode, while Guest 2 represents those guest panellists speaking the most. The majority of women are included in Guest 1 as they predominantly contributed fewer turns than the male guest panellists and Guest 2 does indeed only include one female guest panellist (episode 3, Lauren Laverne). 


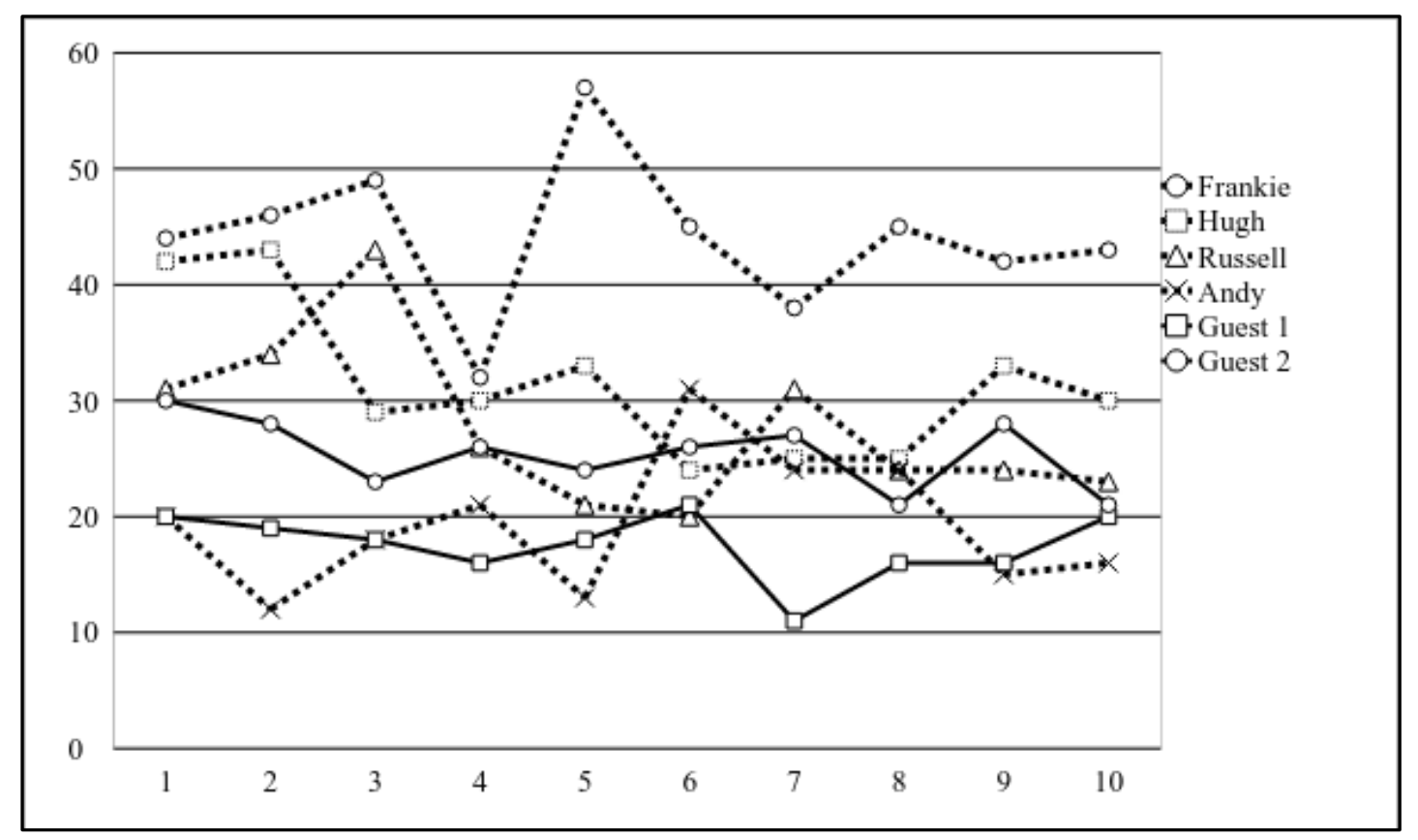

Figure 2. Turn count per panel member

As Figure 2 shows, Frankie Boyle (permanent panellist) contributes most turns throughout the series, with a peak in episode five. It is in this episode that we also see a dip in contributions from the opposing panel team, which includes both Russell Howard and Andy Parsons. While there are peaks and dips for permanent panellists (compare e.g. Hugh and Russell in episodes one to three), the guest panellists show a rather stable distribution. Thus, for the group Guest 2, the number of turns falls in the range between 20 and 30 and for Guest 1 it moves in the range of 10 to 20 turns. The only permanent panellist contributing on such a low level is Andy Parsons in episodes one to five and episodes nine to ten. In episodes six to eight, Andy contributes a significantly higher number of turns, surpassing even Hugh and Russell in episode six. This is, however, the exception rather than the rule, as the subsequent dip in episodes seven and eight demonstrates. From this, one can conclude that in general permanent panellists contribute a higher number of turns than guest panellists. Male guest panellists, however, occasionally come close to or even surpass them in terms of their total number of contributions. For example, in episodes six to nine, we see a convergence of Guest 2 with several permanent panel members.

While the above results partly support the claim that it is difficult for female comedians on Mock the Week to contribute to the discussion, they also show that speaker sex is not the 
only variable influencing a lower contribution rate. Guest panellists tend to be included less than permanent members, with female guest panellists having the least say. In the following, we extend our analysis to study the role interruptions play in our corpus.

\subsection{Interruptions}

In the ten episodes of Mock the Week studied, there are 97 interruptions in total, the majority of which are produced by males interrupting males (84). With regard to the plain frequencies of male-female and female-male interruptions, the number of interruptions used by female speakers to interrupt males is slightly higher (8) than that for males interrupting females (5). Note that since there is only one female panellist per episode, there are consequently no female-female interruptions.

When weighting the number of mixed-sex interruptions to the number of turns produced by men $(2,199)$, therefore accounting for the total number of opportunities that women and men have to interrupt each other, the following picture emerges: $0.4 \%$ of all male turns are interrupted by female speakers and $0.2 \%$ of all male turns are interruptions of female turns, showing that women are more likely to interrupt men than they are to be interrupted by men (albeit, only marginally). For same-sex male interruptions, on the other hand, the rate of interruption amounts to $3.8 \%$. This is mainly due to the fact that male panellists have a higher chance of interrupting each other as there are more male panellists in each episode contributing a higher number of turns than female panellists.

With regard to the individual panellists, interrupters and interruptees are spread more or less evenly across all panellists and no specific idiosyncratic patterns of particular speakers always interrupting the same interlocutors were found. However, we did find that weighted to the total number of turns spoken by guest and permanent panellists, guest panellists interrupt more $(6.3 \%)$ than permanent panellists $(3.7 \%)$, despite having fewer turns and therefore fewer opportunities to interrupt overall. ${ }^{3}$ This could be a sign that given the familiarity of permanent panellists with the show and each other, guest members have to make a greater effort to get a word in and therefore interrupt more. Having said that, it should be remembered that all

\footnotetext{
${ }^{3}$ Four of the guest panellists did not interrupt once: Adam Hills, Ben Norris, Rhod Gilbert and Fiona Allen, all of whom appeared in only one episode each.
} 
female members are guest panellists, which links to our previous point regarding the sex of the interrupter. Dividing the group of guests by speaker sex, the tendency to interrupt is slightly higher for female guest panellists (6.4\%) than for male guest panellists (6.2\%), with frequencies weighted to the total number of turns spoken by female and male guest panellists respectively. Consequently, one may conclude that interruption is in this case influenced by an interplay of role and speaker sex.

In addition to tagging interruptions in the Mock the Week corpus, we also distinguished between three different types of interruptions (see above). Thus, we included values for the function of an interruption and specified whether it was disruptive, supportive or neutral, which allowed us to extract the total number of interruption functions by speaker role (Table $3)$.

Table 3. Interruption functions by speaker role (including weighted frequencies)

\begin{tabular}{|l|r|r|r|r|}
\hline Interrupting & \multicolumn{1}{|l|}{ Disruptive } & \multicolumn{1}{l|}{ Neutral } & \multicolumn{1}{l|}{ Supportive } & \multicolumn{1}{l|}{ TOTAL } \\
\hline Male permanent & $38(2.00)$ & $20(1.05)$ & $12(0.63)$ & $70(3.68)$ \\
\hline Male guest & $16(5.21)$ & $1(0.33)$ & $2(0.65)$ & $19(6.19)$ \\
\hline Female guest & $5(4.00)$ & 0 & $3(2.40)$ & $8(6.40)$ \\
\hline & & & & 97 \\
\hline Being interrupted & Disruptive & Neutral & Supportive & TOTAL \\
\hline Male permanent & $46(2.42)$ & $16(0.84)$ & $14(0.74)$ & $76(4.00)$ \\
\hline Male guest & $9(2.93)$ & $4(1.30)$ & $2(0.65)$ & $15(4.88)$ \\
\hline Female guest & $3(2.40)$ & $1(0.80)$ & $1(0.80)$ & $5(4.00)$ \\
\hline Male unknown & & & & 1 \\
\hline & & & & 97 \\
\hline
\end{tabular}

Table 3 lists the total number of disruptive, neutral and supportive interruptions carried out (interrupting) and received (being interrupted) by male permanent panellists and male or female guest panellists. Here, the plain token numbers are weighted to the total number of turns of each speaker group. When divided according to interruption function, the plain token frequencies are at times significantly reduced, amounting to less than 10 attestations in several of the different categories. Bearing this caveat in mind, Table 3 shows that disruptive interruptions are most frequent overall and the density of their attestation is highest for male guest panellists, both with regard to them interrupting other panellists and being interrupted. At the same time, the density of disruptive interruptions used by female guest panellists is 
twice as high compared to male permanent panellists, which relates to the above finding of guest panellists interrupting more overall. Nevertheless, when studying the addressees' roles, one can see that male permanent and female guest panellists are disruptively interrupted to almost the same extent. In other words, the claim that female panellists on Mock the Week "won't get a word in" (Brand, 2009) is not upheld by the study of interruptions whose function is to cut off another speaker's turn and take the floor from them.

Supportive interruptions are made to add to a previous speaker's point or strengthen their argument. In this category, frequencies are the lowest compared to the other two and one can therefore only tentatively conclude that they seem to be associated with female guest panellists as they have the highest densities in their speech, both as users and recipients. On the other hand, neutral interruptions, which neither disrupt nor support but may occur, for instance, when two speakers start new turns at roughly the same time, have their highest densities with male panellists, being most frequently used by permanent members and mainly associated with male addressees.

\subsection{Interruption in action}

We now take a closer look at several extracts from the corpus and discuss them with reference to the section of the show where they occur. This is because not only is Mock the Week characterised by a certain set up of permanent and guest panellists interacting with each other and the host of the show, but in series five each episode also comprised a certain sequence of show rounds, including 'Headliners,' 'If this is the answer, what is the question?', as well as open question sections generating discussion of the latest news.

The first example is taken from the very beginning of episode one, which, like all episodes in this series, starts with a round of 'Headliners.' In this round, a picture is shown on screen in conjunction with the initial letters of a newspaper headline and the panellists have to guess what the full headline was. Given the competitive nature of this round, it is usually fastpaced with all panellists addressing their headline versions to the host of the show. Example (1) shows the interaction after a picture of former British Prime Minister Gordon Brown was shown, subtitled by the letter sequence G. B. T. C.

(1) Example 'Headliners' 


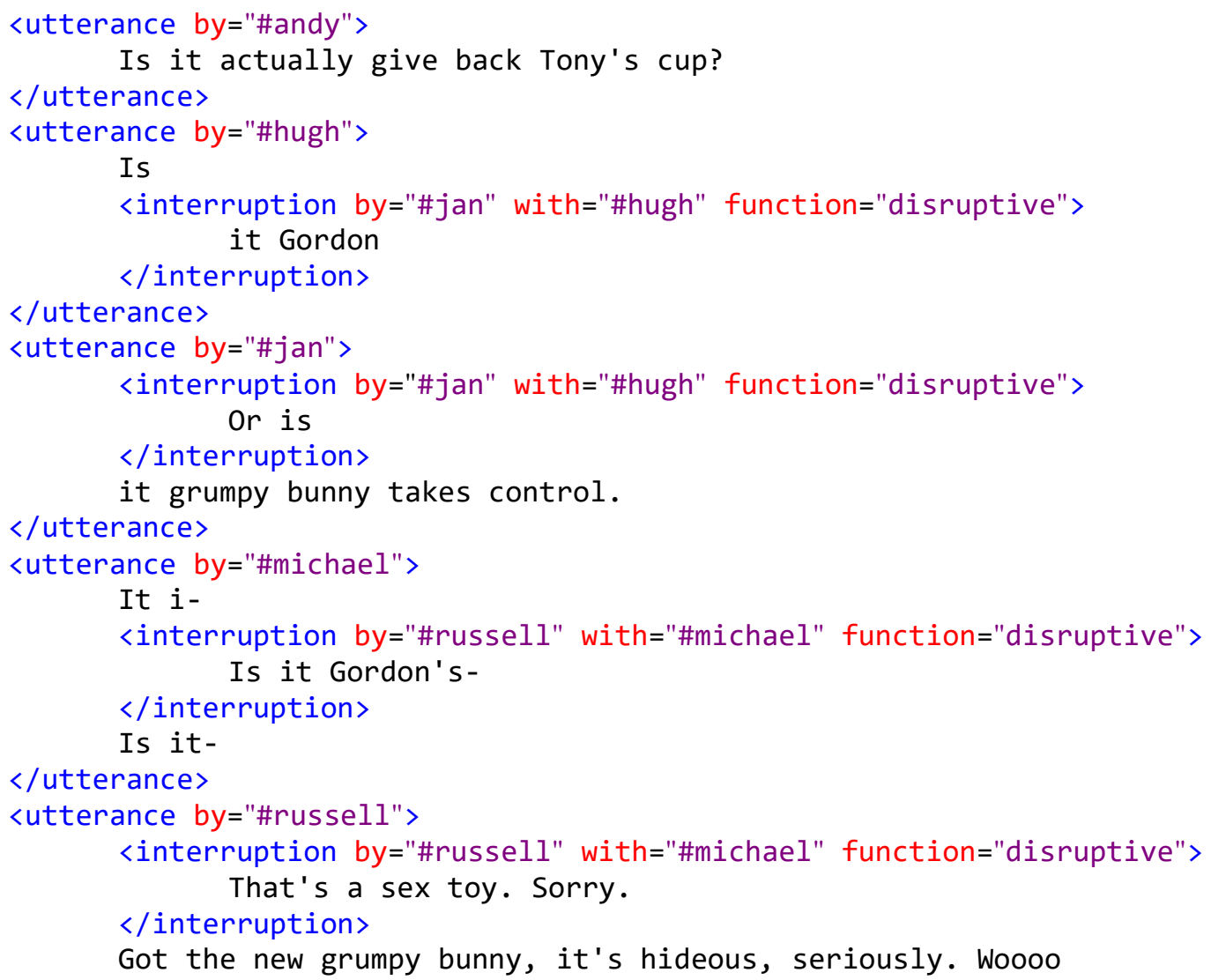

(Mock the Week, series five, episode one, starts at 1:17)

As one can see highlighted in example (1), two disruptive interruptions occur in this short sequence (lines 6-8 and 11-13 for interruption 1, Jan interrupting Hugh, and lines 18-20 and 24-26 for interruption 2, Russell interrupting Michael ${ }^{4}$ ), illustrating the most frequent type of interruption whose density is highest in both male and female guest panellists' speech. First, the guest panellist Jan interrupts Hugh, not allowing him to finish his turn, while she continues to offer her headline solution. Immediately afterwards, Russell interrupts Michael, illustrating the most common addressee pattern for disruptive interruptions, which are mainly received by male guest panellists, as Table 3 shows. Although he relates back to Jan's previous turn, and one can thus see the relevance of his contribution at this specific point of

\footnotetext{
${ }^{4}$ Interruptions are signalled by tags both in the turn of the panellist being interrupted and the one interrupting; interruption tags immediately following each other in the transcript signal the same interruption.
} 
the interaction, he acknowledges the disruptive nature of his interruption by apologising to Michael (line 25).

The set-up of this round predetermines that the panellists from both teams aim to contribute funny versions of the headline in question to ultimately find the actual headline solution, addressing them to Dara O'Briain. That is why interruptions occurring in this part of the show ( $8 \%$ of the total number of attestations in the corpus) are mainly due to two panellists competing for the floor and wanting to have their headline version heard first, as is the case for the first interruption in example (1). The second interruption in example (1) illustrates slightly different dynamics as it involves the panellists reacting to and interacting with each other. Thus, they diverge slightly from the main focus of the round, in this case for Russell to comment on what his team member Jan has just said, not with the aim of providing the correct solution but contributing to the overall aim of the show, which is the creation of humour and the humorous discussion of the news.

Once the correct solution for the round 'Headliners' has been found, the two teams usually continue discussing the topic raised. It is in this part of the show, which develops the topic through an open discussion among all panellists and the host, that a quarter of all interruptions in the data occur. Example (2) illustrates this: Dara O'Briain first provides some additional information on the topic of floods in different parts of England. While he is finishing his turn, Lauren Laverne overlaps with him once (lines 7-9 and 14-16), but then waits until his turn is complete to continue her own. Lauren's contribution is in turn interrupted by the permanent panellist Hugh Dennis (lines 20-22 and 25-27).

\section{Example (2) (following Headliners - same topic)}

1

5

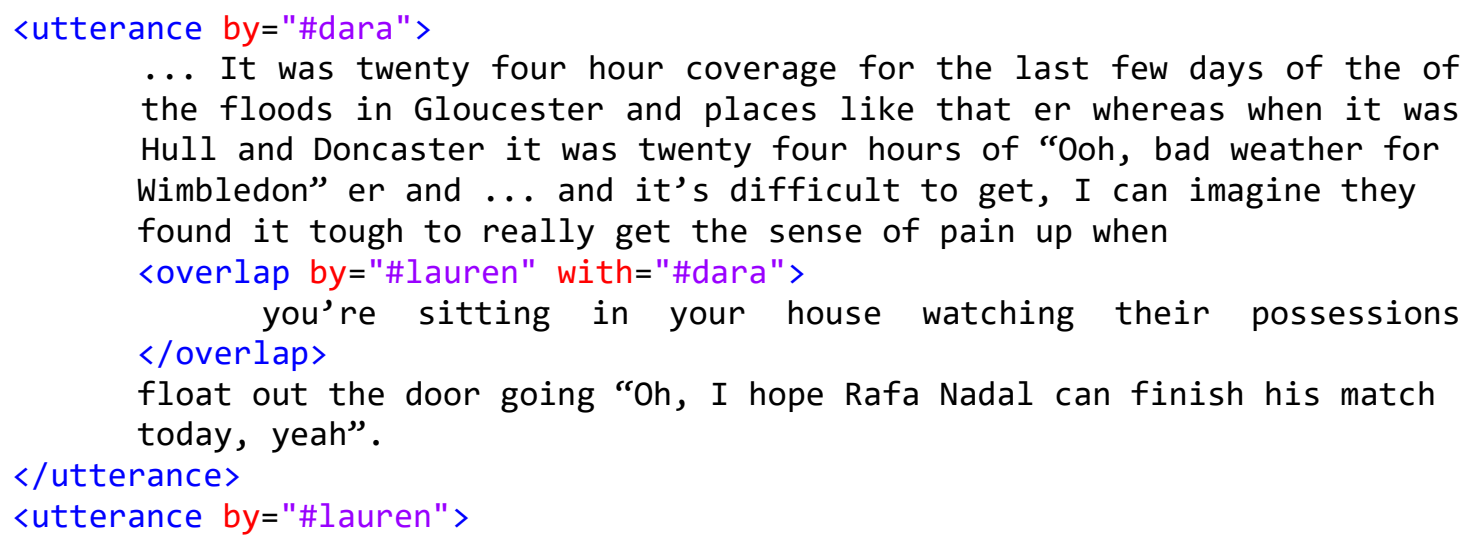


(Mock the Week, series five, episode three, starts at 6:26)

As example (2) shows, Hugh's interruption is of a clearly supportive nature; instead of claiming the floor for his own sake, he voices an argument in support of Lauren's contribution, claiming that the news correspondent for the north of England does not have a boat. The fact that his is a supportive interruption is further confirmed by Lauren's immediate reaction, agreeing with what Hugh has said. Despite low plain frequencies overall, this type of interruption is mainly associated with female panellists (Table 3).

In series five, the round 'If this is the answer, what is the question?' appeared in the main body of the show. It is similar to 'Headliners' in that all panellists play this round and have to guess the correct solution (in this case the question to match a specific answer revealed by the host Dara O'Briain). One of the guest panellists is asked to pick one out of six categories, including sports, world news or politics. This then determines the topic around which the round is organised. In this part of the show and the discussions that follow it, almost a fifth of all interruptions occur. Example (3) illustrates two interruptions appearing immediately after each other in this round in episode eight. In this case the category was 'nature' and the answer was 'sparrows, otters and hedgehogs.' 
Example (3) 'If this is the answer, what is the question?'

1 <utterance by="\#andy"> Who are the entrants in Simon Cowell's new TV show 'The Woodland 's got talent.'

$</$ utterance $>$

5 <utterance by="\#russell">

Name three of the deadliest gangs in Royal Tunbridge Wells

$</$ utterance $>$

<utterance by="\#ed">

<interruption by="\#frankie" with="\#ed" function="neutral">

10 what -

$</$ interruption>

$</$ utterance $>$

<utterance by="\#frankie">

<interruption by="\#frankie" with="\#ed" function="neutral">

Is it,

$</$ interruption>

as a child, what did I dress in military uniforms to re-enact the Battle of Stalingrad; the German forces being played by a lawnmower?

20 <utterance by="\#dara">

Any of you got the correct answer?

$</$ utterance $>$

<utterance by="\#russell">

accord-

25

<interruption by="\#ed" with="\#russell" function="disruptive">

-ing to

$</$ interruption $>$

$</$ utterance $>$

<utterance by="\#ed">

30

〈interruption by="\#ed" with="\#russell" function="disruptive"> What 's,

$</$ interruption>

what 's been put, what 's recently been put on the endangered species list?

$35</$ utterance $>$

<utterance by="\#dara">

〈overlap by="\#russell" with="\#dara">

$</ o v e r l a p>$

That 's absolutely right,

40

well done Ed Byrnes. Congratulations, very good.

$</$ utterance $>$

<utterance by="\#russell">

〈overlap by="\#russell" with="\#dara"〉 Yes it is.

45

$</$ overlap>

$</$ utterance $>$

(Mock the Week, series five, episode eight, starts at 15:44) 
As in the round 'Headliners,' the panellists are addressing their answers to the host and they initially suggest humorous questions rather than immediately aiming for the right one. This round is therefore similarly competitive, in that panellists try to get a turn and compete with each other for the floor, aiming to contribute funny, but ultimately unlikely, questions. The first interruption (lines 9-11 and 14-16) in example (3) is tagged as having a neutral function. This is because Ed and Frankie both start speaking at about the same time and the interruption does not significantly disrupt the previous turn. While the guest panellist Ed Byrne's turn is interrupted, the permanent panellist Frankie Boyle continues his turn without hesitation or repetition. This is different from the second interruption in example (3), where permanent panellist Russell Howard starts his turn but is then immediately interrupted by his team member (lines 25-27), guest panellist Ed Byrne, who first produces two false starts before formulating his question (lines 30-32), a sign that he is trying to keep the floor after taking it from Russell. While both of them are on the same team, they still compete as to who knows the correct answer. The interruptions in (3) thus illustrate the most prominent pattern for neutral interruptions, which are mainly produced by male permanent panellists and received by male guest panellists, and disruptive interruptions, which are mainly produced by male guests, as Table 3 shows.

More than $40 \%$ of the interruptions appear when the news is being discussed through open questions addressed to the panellists by the host of the show, which is sometimes accompanied by pictorial evidence. This is illustrated by example (4), where Dara O'Briain first asks a question, which is then supported by a picture showing a bank robber covered in leaves and branches. In the comparatively short sequence in example (4), which is only about forty seconds long, a total of four interruptions are attested. This shows that when interruptions occur in Mock the Week, they tend to cluster. The first interruption occurs when permanent panellist Andy Parsons provides the correct answer and pauses briefly before wanting to continue his turn. This is when he is interrupted by guest panellist Jan Ravens (lines 8-10 and 13-15), who offers an explanation as to why the robber would have dressed up as a tree, thereby supporting Andy's last statement. Andy immediately afterwards interrupts Dara (lines 20-22 and 25-27) when he has presented the picture of the bank robber wearing a tree branch. As the showing of the man's photo entailed laughter both from the audience and 
the panel, the function of this interruption was classed as neutral as any transition relevance point would have been drowned by the surrounding noise.

Example (4) News discussion

1 <utterance by="\#dara">

Eh, how did the natural world cause problems for the financial world this week?

5 <utterance by="\#andy" immediate="yes">

This was qu- This was the bloke who tried to rob a bank wearing a tree branch. He- he dressed up as an ent effectively, had n't he? <interruption by="\#jan" with="\#andy" function="supportive"> $\mathrm{He}-$

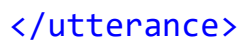




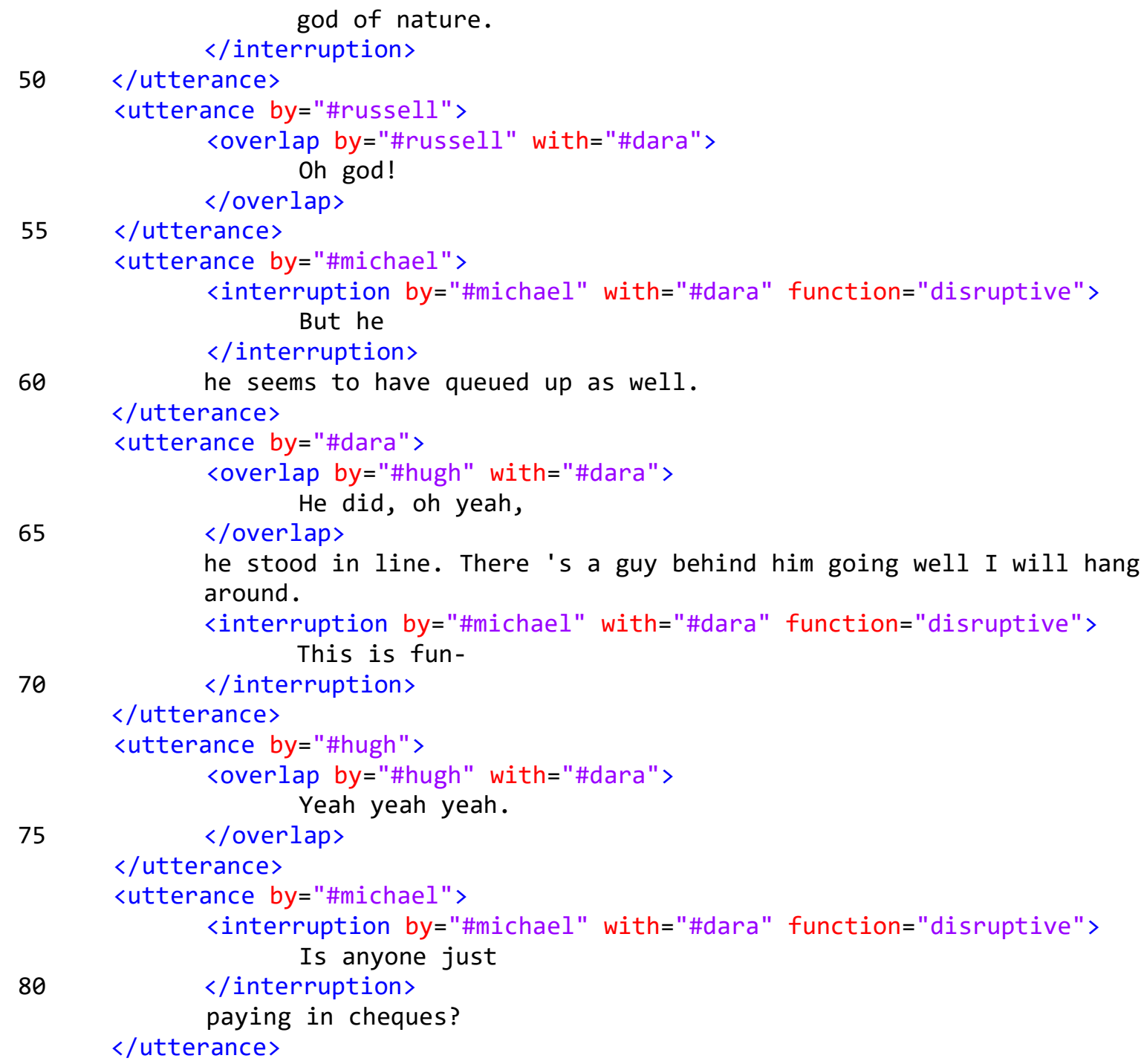

(Mock the Week, series five, episode one, starts at 22:10)

The final two disruptive interruptions in (4) are produced by the guest panellist Michael McIntyre (the first on lines 47-49 and 57-59; the second on lines 68-70 and 78-80) . Both of these are classed as disruptive as he stops Dara from continuing his turns twice. At the same time, Michael's contributions are topical and he adds comical observations and suggestions of what may have happened on the day of the robbery, thereby contributing to the overall aim of the show of producing humorous interactions. As a consequence, while he disruptively interrupts the host of the show, his interruptions do not have a negative effect on the development of the sequence and eliciting laughter from the audience. This is evidenced, for instance, by Dara supporting Michael's point after his first interruption, which is also 
reinforced by Hugh Dennis, overlapping the beginning of Dara's turn with affirming discourse particles. Thus, even though interruptions in the main body of Mock the Week may have the effect of cutting another panellist's turn short, rendering their function disruptive, they may contribute positively to the creation of humour and support the ultimate aim of the show.

\section{Discussion and future directions}

This study set out to gain sociolinguistic insights into the comedy panel show Mock the Week. It was conducted in the understanding that this show is partially-scripted as well as heavily edited and was meant to fill a gap in research, given that it focuses on data that diverges from the traditional type of sociolinguistic data and that has attracted little attention in the field. On Mock the Week, interaction between interlocutors happens under very specific circumstances, where the main aim of the show's panellists is the creation of humour. It is through the analysis of the end product, the broadcast episodes of series five compiled into an XMLannotated corpus totalling 56,353 words, that we investigated the influence of different social variables on speech volume and conversational contribution, on the one hand, and the use and function of interruptions, on the other hand. The intention was to empirically examine conversational dominance in comedy shows as displayed in the final edited version.

In the analysis presented here, we made the decision to focus on a series of Mock the Week where female panellists were relatively well represented (albeit, far less than male panellists). Our expectation was that this would offer a more balanced perspective of linguistic practice on the show. For example, with six panellists (one female, five males), it would be reasonable to assume that the number of contributions would be roughly proportional. However, our results demonstrate that female guest panellists contribute far less than male panellists, amounting to $4 \%$ of the total number of words spoken and $5 \%$ of all turns, and well below what might be expected given the overall number of female panellists across the entire series (see Table 2) or even within a single episode. There could be two reasons for this: the first is that female panellists simply do not contribute to the same extent as male panellists; the second is that women do contribute frequently, but their contributions are not included in the final televised version. While we do not have access to the pre- 
recorded data and therefore cannot substantiate our claims, one of the implications could be that editors and directors are (un)consciously adopting a schema of norms where men are viewed as being funnier than women; this would undoubtedly colour the decision to edit in favour of men.

At the same time, however, our study has shown that the variable of situational role needs to be taken into account in addition to speaker sex, as guest panellists speak less than permanent panellists. Our results thus demonstrate that guest panellists, and more specifically female guest panellists, are granted (or make use of) the least speaking time overall. Likewise for interruptions, our study revealed a tendency of guests (both male and female) to disruptively interrupt most frequently, indicating that it may be more difficult for them to start a turn than for permanent panellists, who are familiar with the show. On the other hand, when focusing on the recipients of interruptions, that is the interruptees, it turns out that male permanent and female guest panellists are disruptively interrupted to almost the same extent. Thus, our results for disruptive interruptions do not uphold Jo Brand's (2009) claim that women are at a disadvantage compared to male regular panellists on the show.

Finally, the genre has an effect on the interpretation of our data in addition to the social variables discussed above. Thus, we found differences in the density of interruptions in the different parts of the show: they appear repeatedly in competitive sections such as 'Headliners' and 'If this is the answer, what is the question?', where panellists compete for the floor to have their jokes heard and finally to name the correct solution. Almost two thirds of all interruptions, however, appear in open discussion rounds of news related topics. At this point in the show, the competitive element is not foregrounded by the activity but is inherently still present as all panellists want to be perceived as funny, which impacts their professional reputation and pertains to the fact that they are ultimately at work when participating in Mock the Week. At the same time, it may be the case that disruptive interruptions, despite cutting off another participant's turn, contribute to the ultimate aim of the show, which is the creation of humour and humorous interaction. This may have a positive effect on the sequential progression of the show and the desired audience reaction.

Our findings for Mock the Week are in line with previous research in the field (cf. O'Barr and Atkins, 1980; Eckert, 2000; Zimman, 2014), that focusing on aspects of identity other than speaker sex allows us to develop a more nuanced picture of linguistic practices that 
goes beyond a straightforward explanation of 'male speakers do X, female speakers do Y.' That said, such findings tend not to have much impact beyond academia, resulting in the complexities of linguistic practice being reduced to narratives based on prevailing folklinguistic views (Lawson, 2016).

This can be seen most clearly in how Jo Brand's comments about comedians on Mock the Week ended up being primarily framed in terms of the position of women in the comedy industry more generally and the steps that should be taken to address such inequalities of representation and participation. One of the most high-profile interventions in this regard was the announcement by Danny Cohen (the then Director of Television at the BBC) in February 2014 that the BBC would commit to ending all-male line-ups on comedy panel shows. This decision meant that future recordings of shows like Mock the Week would have at least one female participant. While the $\mathrm{BBC}$ is certainly to be commended for attempting to tackle the low rate of female representation in comedy, our results suggest that simply increasing the number of female panellists fails to address the deeper issues at play. We therefore offer some tentative ways forward in addressing the relative unease that female panellists in particular have voiced with regard to appearing on shows like Mock the Week.

First, production companies, directors, editors, script writers, and others could, for example, examine the kind of interactional styles encouraged in the context of comedy panel shows and offer guidance to both male and female as well as permanent and guest panellists in relation to floor and topic management. This may relate to the fast-paced interactional norm and the competition for air time, which may be perceived as aggressive when viewed within a mainstream conversational context but may fulfil other functions within the confines of a comedy panel show. Alternatively, more attention could be paid to whether guest panellists are edited out and investigating what kind of systems could be put in place to alleviate this. If organisations like the $\mathrm{BBC}$ are truly committed to improving the visibility of female panellists, then additional measures such as these should be considered, because having female panellists does not guarantee them receiving proportional screen time, as our results demonstrate. Ultimately, it is only through the critical reflection of how language is used in comedy shows such as Mock the Week that meaningful progress will be made in terms of linguistic equality. Until that time, token efforts in increasing the number of female panellists simply mask the underlying problem. 


\section{Bibliography}

Anderson, K.J., Leaper, C. 1998. Meta-analyses of gender effects on conversational interruption: Who, what, when, where, and how. Sex Roles 39 (3/4), 225-252.

Attardo, S. 2015. Humor and laughter. In D. Tannen, H. E. Hamilton and D. Schiffrin (eds.). The Handbook of Discourse Analysis. Chicester: John Wiley \& Sons, Inc., 168188.

Baker, P. 2010. Sociolinguistics and Corpus Linguistics. Edinburgh: Edinburgh University Press.

Bamman, D., Eisenstein, J., Schnoebelen, T. 2014. Gender identity and lexical variation in social media. Journal of Sociolinguistics 18 (2), 135-160.

Bemiller, M.L., Schneider, R.Z. 2010. It's not just a joke. Sociological Spectrum 30 (4), 459479.

Benedictus, L. 2012. Where are all the female stand-ups? Accessed 25 February 2015. Available from: http://www.theguardian.com/stage/2012/mar/20/female-standupcomedy-void.

Bird, C. 2010. Women can't tell jokes. In J. Holmes and M. Marra (eds.). Femininity, Feminism and Gendered Discourse. Newcastle upon Tyne: Cambridge Scholars Publishing, 83-107.

Bohn, E., Stutman, R. 1983. Sex-role differences in the relational control dimension of dyadic interaction. Women's Studies in Communication 6 (2), 96-104.

Brand, J. 2009. Women - beware panel shows! Accessed 25 February 2015. Available from: http://www.theguardian.com/culture/2009/jun/10/television-panel-shows-jo-brand.

Bressler, E.R., Martin R.A., Balshine, S. 2006. Production and appreciation of humor as sexually selected traits. Evolution and Human Behavior 27, 121-130.

Brooks, V. 1982. Sex differences in student dominance behavior in female and male professors' classrooms. Sex Roles 8 (7), 683-690.

Burnett, D. 2014. Why do people believe women aren't funny? Accessed 18 May 2015. Available from: http://www.theguardian.com/science/brainflapping/2014/feb/11/women-arent-funny-why-do-people-believe-this.

Cameron, D. 2006. On Language and Sexual Politics. Oxon: Routledge.

Cameron, D. 2006. Theorising the female voice in public contexts. In J. Baxter (ed.). Speaking Out: The Female Voice in Public Context. Basingstoke: Palgrave Macmillan, $3-20$.

Cameron, D. 2007. The Myth of Mars and Venus. Oxford: Oxford University Press.

Coates, J. 2003. Men Talk: Stories in the Making of Masculinities. Oxford: Blackwell.

Coates, J. 2004. Women, Men and Language ( $3^{\text {rd }}$ edition). London: Longman.

Collinson, D.L. 1988. Engineering humour: Masculinity, joking and conflict in shop-floor relation. Organizational Studies 9 (2), 181-199.

Crawley, J. 2013. Not quite so intelligent. Accessed 3 February 2016. Available from: http://www.dailymail.co.uk/tvshowbiz/article-2397834/Alan-Davies-admitscontestants-questions-advance-hit-panel-shows-QI-Mock-Week.html.

Eckert, P. 2000. Language Variation as Social Practice: The Linguistic Construction of Identity in Belten High. Oxford: Wiley-Blackwell. 
Eckert, P., Podesva, R. 2011. Sociophonetics and sexuality: Towards a symbiosis of sociolinguistics and laboratory phonology. American Speech 86 (1), 6-13.

Edelsky, C. 1981. Who's got the floor? Language in Society 10 (3), 383-421.

Feeney, N. 2013. Why aren't there more women on the top-earning comedians list? Accessed 25 February 2015. Available from: http://www.forbes.com/sites/nolanfeeney/2013/07/11 /why-arent-there-more-women-on-the-top-earning-comedians-list/.

Fishman, P. 1978. The work women do. Social Problems 25 (4), 397-406.

Gambacorta, D., Ketelaar, T. 2013. Dominance and deference: Men inhibit creative displays during mate competition when their competitor is strong. Evolution and Human Behavior 34, 330-333.

Greengross, G. 2014. Male production of humor produced by sexually selected psychological adaptations. In V.A. Weekes-Shackelford and T.K. Shackelford (eds.). Evolutionary Perspectives on Human Sexual Psychology and Behavior. New York: Springer, 173196.

Greengross, G., Miller G.F. 2009. The big five personality traits of professional comedians compared to amateur comedians, comedy writers, and college students. Personality and Individual Differences 47 (2), 79-83.

Goldberg, J. 1990. Interrupting the discourse on interruptions: An analysis in terms of relationally neutral, power- and rapport-oriented acts. Journal of Pragmatics 14 (6), 883-903.

Harris, S. 1995. Pragmatics and power. Journal of Pragmatics 23 (2), 117-135.

Henley, N.M., Kramarae, C. 1991. Gender, power and miscommunication. In N. Coupland, H. Giles and J.M. Wieman (eds.). Miscommunication and Problematic Talk. Newbury Park, CA: Sage, 18-43.

Heritage, J. 2005. Conversation analysis and institutional talk. In K. Fitch and R. Sanders (eds.). Handbook of Language and Social Interaction. Mahwah, N.J.: Lawrence Erlbaum Associates, 103-148.

Hitchens, C. 2007. Why women aren't funny. Accessed 25 February 2015. Available from: https://web.archive.org/web/20150113063723/http://www.vanityfair.com/culture/featur es/2007/01/hitchens200701.

Johnson, S. 1997. Theorizing language and masculinity: A feminist perspective. In S. Johnson and U. Meinhof (eds.). Language and Masculinity. Oxford: Blackwell, 8-26.

Kalviknes Bore, I. 2010. (Un)funny women: TV comedy audiences and the gendering of humour. European Journal of Cultural Studies 13 (2), 139-154.

Kehily, M.J., Nayak, A. 1997. 'Lads and laughter': Humour and the production of heterosexual hierarchies. Gender and Education 9 (1), 69-88.

Khan, U. 2009. TV panel shows are too 'male dominated', claims Victoria Wood. Accessed 25 February 2015. Available from: http://www.telegraph.co.uk/culture/culturenews/5478241/TV-panel-shows-are-toomale-dominated-claims-Victoria-Wood.html.

Knight, N. 2013. Evaluating experience in funny ways: how friends bond through conversational humour. Text \& Talk 33 (4-5), 553-574.

Lakoff, R. 1975. Language and Women's Place. New York: Harper \& Row. 
Lang, N. 2015. Stop asking why hot women aren't funny. Accessed 4 January 2016. Available from: http://www.dailydot.com/opinion/michael-eisney-goldie-hawn-sexismcomedy/

Lawson, R. 2016. A different drum: Social media and the communication of sociolinguistic research. In R. Lawson and D. Sayers (eds.). Sociolinguistic Research: Application and Impact. Oxon: Routledge, 171-192.

Leet-Pellegrini, H.M. 1980. Conversational dominance as a function of gender and expertise. In H. Giles, W.P. Robinson and P.M. Smith (eds.). Language: Social Psychological Perspectives. Oxford: Pergamon Press, 97-104.

Logan, B. 2013. Ross Noble mocks Mock the Week. Accessed 25 February 2015. Available from: http://www.theguardian.com/stage/2013/oct/29/ross-noble-mock-the-week-tvcomedy.

Martin, N. 2008. Comedy panel shows are 'testosterone fuelled', says BBC Radio 4 presenter. Accessed 25 February 2015. Available from: http://www.telegraph.co.uk/news/uknews/3452529/Comedy-panel-shows-aretestosterone-fuelled-says-BBC-Radio-4-presenter.html.

McElhinny, B. 2003. Theorizing gender in sociolinguistics and linguistic anthropology. In J. Holmes and M. Meyerhoff (eds.). The Handbook of Language and Gender. Oxford: Blackwell Publishing Ltd, 21-42.

Mullany, L. 2010. Im/politeness, rapport management and workplace culture. In F. BargielaChiappini and D.Z. Kádár (eds.). Politeness across Cultures. Basingstoke: Palgrave Macmillan, 61-84.

Nissim, M. 2011. Andy Parsons: 'Some comedians don't like Mock the Week edit'. Accessed 25 February 2015. Available from: http://www.digitalspy.co.uk/tv/news/a349715/andyparsons-some-comedians-dont-like-mock-the-week-edit.html\# p5jcCTovvgc5WG.

O’Barr and Atkins 1980. "Women's language" or "powerless language"? In S. McConnellGinet, R. Borker and N. Furman (eds.). Women and Language in Literature and Society. New York: Praeger, 93-110.

Octigan, M., Niederman, S. 1979. Male dominance in conversations. Frontiers: A Journal of Women Studies 4 (1), 50-54.

Queen, R. 2013. Working with performed language: Movies, television, and music. In C. Mallinson, B. Childs and G. Van Herk (eds.). Data Collection in Sociolinguistics: Method and Application. Oxon: Routledge, 217-227.

Rainey, S. 2012. Funny women: London's female comedians. Accessed 25 February 2015. Available from: http://www.telegraph.co.uk/travel/destinations/europe/uk/london/9253148/Funnywomen-Londons-female-comedians.html.

Sacks, H., Schegloff, E., Jefferson, G. 1974. A simplest systematics for the organisation of turn-taking for conversation. Language 50 (4), 696-735.

Simpson, R. 2000. Gender mix and organisational fit: How gender imbalance at different levels of the organisation impacts on women managers. Women in Management Review. 15 (1), 5-18.

Smith-Lovin, L., Brody, C. 1989. Interruptions in group discussions: The effects of gender and group composition. American Sociological Review 54 (June), 424-435.

Smurthwaite, K. 2012. Stop laughing at sexism. Accessed 3 February 2016. Available from: http://www.bbc.co.uk/programmes/b01hxmx5. 
Spender, D. 1980. Man Made Language. London: River Orams Press.

Tannen, D. 1983. When is an overlap not an interruption? One component of conversational style. In R.J. Di Pietro (ed.). Language Studies: Symposium Proceedings (Delaware Symposia on Language Studies). London: Associated University Presses Ltd., 119-129.

West, C. 1984. When the doctor is a 'lady': Power, status and gender in physician-patient encounters. Symbolic Interaction 7 (1), 87-106.

Wilbur, J.C., Campbell, L. 2013. Swept off their feet?: Females' strategic behaviour as a means of supplying the broom. In M.L. Fisher, J.R. Garcia and R. Sokol Chang (eds.). Evolution's Empress: Darwinian Perspectives on the Nature of Women. Oxford: Oxford University Press, 330-344.

Woods, N. 1989. Talking shop: Sex and status as determinants of floor apportionment in a work setting. In J. Coates and D. Cameron (eds.). Women in their Speech Communities: New Perspectives on Language and Sex. London: Longman, 141-157.

Zimman, L. 2014. The discursive construction of sex: Remaking and reclaiming the gendered body in talk about genitals among trans men. In L. Zimman, J. L. Davis and J. Raclaw (eds.). Queer Excursions: Retheorizing Binaries in Language, Gender, and Sexuality. Oxford: Oxford University Press, 13-34.

Zimmerman, D.H., West, C. 1975. Sex roles, interruptions and silences in conversation. In B. Thorne and N. Henley (eds.). Language and Sex: Difference and Dominance. Rowley, Massachusetts: Newbury House, 105-129. 